Check for updates

Cite this: RSC Adv., 2017, 7, 53126

Received 28th September 2017 Accepted 2nd November 2017

DOI: 10.1039/c7ra10731e

rsc.li/rsc-advances

\section{Tin-based materials supported on nitrogen-doped reduced graphene oxide towards their application in lithium-ion batteries $\uparrow$}

\author{
Xiaoxia Zuo, ${ }^{\mathrm{a}}$ Bao Li, ${ }^{a}$ Kun Chang, ${ }^{\text {tb }}$ Hongwei Tang ${ }^{\mathrm{a}}$ and Zhaorong Chang (D) *a \\ Recently, nitrogen-doped graphene has attracted significant attention for application as an anode in \\ lithium-ion batteries due to effective modulation of the electronic properties of graphene. Herein, we \\ report a facile route to successfully synthesize a series of tin-based materials (including $\mathrm{Sn}, \mathrm{SnO}_{2}$, and \\ $\mathrm{SnS}_{2}$ ) supported on $\mathrm{N}$-doped reduced graphene oxide (N-rGO). Field emission scanning electron \\ microscopy (FESEM) and transmission electron microscopy (TEM) images indicated that the Sn-based \\ materials were uniformly and tightly dispersed on the surface of N-rGO. When used as an anode in LIBs, \\ the electrochemical performances of the proposed electrodes were systematically investigated and \\ compared. The results show that among these electrodes, $\mathrm{SnS}_{2} / \mathrm{N}-\mathrm{rGO}$ with a matched layered structure \\ delivers the best performance with not only high specific capability but also excellent cycling stability.
}

\section{Introduction}

Rechargeable lithium-ion batteries (LIBs) are a promising power technology for future applications. They have also attracted extensive attention as power sources for high-power tools and electric vehicles. Graphitic materials are extensively used as commercial anode materials for LIBs due to their flat and low potential profile as compared to that of lithium and structural stability during cycling. However, the small theoretical specific capacity of graphite $\left(372 \mathrm{~mA} \mathrm{~h} \mathrm{~g}^{-1}\right)$ necessitates the search of alternative negative electrodes. ${ }^{1}$ During the past few decades, numerous research efforts have been carried out towards exploring novel anode materials, such as amorphous carbon, metal oxides, metal sulfides, and metals or alloys, with high specific capacity; ${ }^{2-8}$ moreover, ideal electrodes that possess not only high capacity but also lower potential profile have been prepared using tin (Sn)-based and silicon (Si)-based materials, as shown in Fig. S1 (ESI). $\dagger$ However, the large volume changes of both metals during the lithiation process restrict the improvement in cycling stability, especially for Si-based electrodes in which the volume change can reach up to $420 \%$, severely destroying the structure of the electrodes. ${ }^{9-13}$

Sn-based materials have attracted growing research interest for use in LIB anodes due to their multi-type compounds such

${ }^{a}$ Collaborative Innovation Center of Henan Province for Green Manufacturing of Fine Chemicals, School of Chemistry and Chemical Engineering, Henan Normal University, Xinxiang 453007, P. R. China.E-mail: czr_56@163.com

${ }^{b}$ National Institute for Materials Science (NIMS), 1-1 Namiki, Tsukuba, Ibaraki, 305o044, Japan.E-mail: chang.kun@nims.go.jp

$\dagger$ Electronic supplementary information (ESI) available. See DOI: 10.1039/c7ra10731e as $\mathrm{SnO}_{2}$ and $\mathrm{SnS}_{2}$, which can buffer the large volume change to some extent. ${ }^{\mathbf{1 4 - 1 7}}$ Moreover, the discovery of reduced graphene oxide (rGO) in recent years has led to the development of a significant number of graphene-based metal, metal oxides, or metal sulfides for use as LIB anodes due to the unique physical and chemical properties and potential of rGO for applications in electronic devices and sensors. The results have generally been promising towards the improvement of their specific capacity and cycling stability. ${ }^{\mathbf{8}, 18-20}$ To further enhance the properties of rGO, element (such as sulfur, boron, and nitrogen) doping via chemical substitution has been used beyond just morphology and size control, and nitrogen doping is shown to be particularly effective in modulating the electronic properties of graphene. ${ }^{21}$ Based on previous reports on Sn-based materials supported on rGO or nitrogen-doped rGO (N-rGO), the most frequently used preparation method is to use rGO as a template and subsequently subject it to a reduction reaction to form $\mathrm{Sn}$ based rGO composites. ${ }^{22-30}$ Although Sn-based materials prepared using this method can be uniformly dispersed on the surface of rGO, the number of remaining oxygen functional groups on rGO will restrict the electronic conductivity and electrochemical performance for the LIB anodes. ${ }^{21}$

Therefore, our current study was aimed at using the asprepared rGO and N-rGO obtained via a thermal exfoliation method as the templates to synthesize Sn-based materials supported on rGO or N-rGO. However, this attempt was unsuccessful while preparing $\mathrm{SnO}_{2} / \mathrm{rGO}$, where the $\mathrm{SnO}_{2}$ nanoparticles could not be directly anchored on the surface of rGO. This may be attributed to the smooth surface of rGO obtained via the thermal exfoliation method. Herein, a series of Sn-based materials (including $\mathrm{Sn}, \mathrm{SnO}_{2}$, and $\mathrm{SnS}_{2}$ ) supported on $\mathrm{N}$-rGO were successfully synthesized. Field emission scanning 
electron microscopy (FESEM) and transmission electron microscopy (TEM) images indicated that the Sn-based materials were uniformly and tightly dispersed on the surface of N-rGO. When used as LIB anodes, the electrochemical performance of the proposed electrodes was systematically investigated and compared. The results show that among these electrodes, $\mathrm{SnS}_{2} / \mathrm{N}-\mathrm{rGO}$ with a matched layered structure delivered the best performance, with not only high specific capability but also excellent cycling stability.

\section{Experimental}

\subsection{Synthesis of rGO and N-rGO}

RGO and N-rGO were prepared following literature procedures. ${ }^{21}$ Briefly, graphite oxide powder was first synthesized using the modified Hummers method. ${ }^{31}$ Then, the graphite oxide powder was heated at $1050{ }^{\circ} \mathrm{C}$ for $30 \mathrm{~s}$ under an $\mathrm{Ar}$ atmosphere to obtain rGO. N-rGO was further obtained by heating rGO under high purity ammonia mixed with $\mathrm{Ar}$ at $900{ }^{\circ} \mathrm{C}$ for $4 \mathrm{~h}$.

\subsection{Synthesis of the Sn-based N-rGO composites}

To synthesize the $\mathrm{SnO}_{2} / \mathrm{N}-\mathrm{rGO}$ composite, $0.38 \mathrm{~g}$ of $\mathrm{SnCl}_{2}$ and $2 \mathrm{~mL}$ of $0.5 \mathrm{M} \mathrm{HCl}$ were dissolved in $80 \mathrm{~mL}$ of deionized water, and then, the abovementioned N-rGO powder was added to the mixture. After ultrasonication and stirring for $30 \mathrm{~min}$, the mixture was transferred to a $100 \mathrm{~mL}$ Teflon-lined stainless steel autoclave, sealed tightly, and heated at $180{ }^{\circ} \mathrm{C}$ for $12 \mathrm{~h}$. After cooling down to room temperature naturally, the black precipitate was obtained by centrifugation, washed with deionized water and ethanol, and then dried in a vacuum oven at $80^{\circ} \mathrm{C}$ for $24 \mathrm{~h}$. Finally, the products were annealed at $300^{\circ} \mathrm{C}$ for $1 \mathrm{~h}$ under an $\mathrm{Ar}$ atmosphere. In the control experiment, the Sn/N-rGO composite was also prepared using the same abovementioned procedure with $\mathrm{N}_{2} \mathrm{H}_{4}$ and $\mathrm{H}_{2}$ protection in the synthetic route, and the $\mathrm{SnS}_{2} / \mathrm{N}$-rGO composite was prepared using the same procedure with $\mathrm{L}$-cysteine as the $\mathrm{S}$ source.

\subsection{Characterization}

Samples were characterized via X-ray diffraction (XRD; Rigaku RU-200BVH diffractometer employing a $\mathrm{Cu}-\mathrm{K}_{\alpha}$ source), field emission scanning electron microscopy (FESEM, Hitachi S4800), transmission electron microscopy (TEM, TECNAI G2 F30, Japan), energy dispersive X-ray spectroscopy (EDX, GENESIS 4000), Raman spectroscopy (Horiba-Jovin Yvon T64000) and X-ray photoelectron spectroscopy (XPS, ULVACPHI, Japan).

\subsection{Electrochemical measurements}

The negative electrodes for the battery tests were composed of Sn-based materials, acetylene black, and polyvinylidene fluoride (PVDF) in a weight ratio of $75: 10: 15$. The mixture of the active material, acetylene black, and PVDF was ground for $2 \mathrm{~h}$ in an agate mortar. The mixture was then dried in a vacuum oven at $80^{\circ} \mathrm{C}$ for $4 \mathrm{~h}$ to remove any moisture. After this, NMP was added

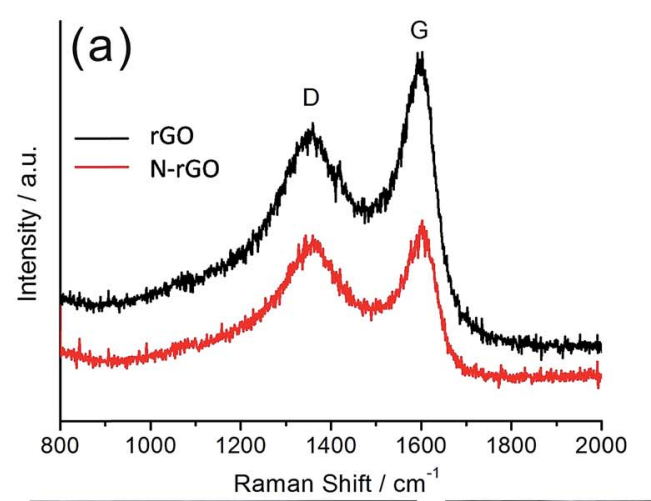

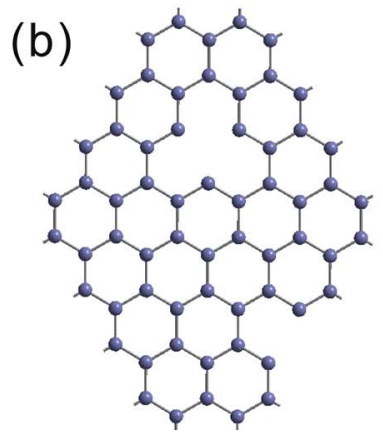

rGO

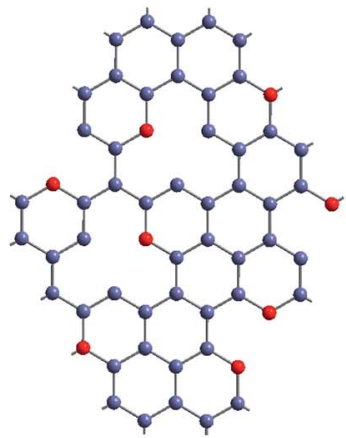

N-rGO
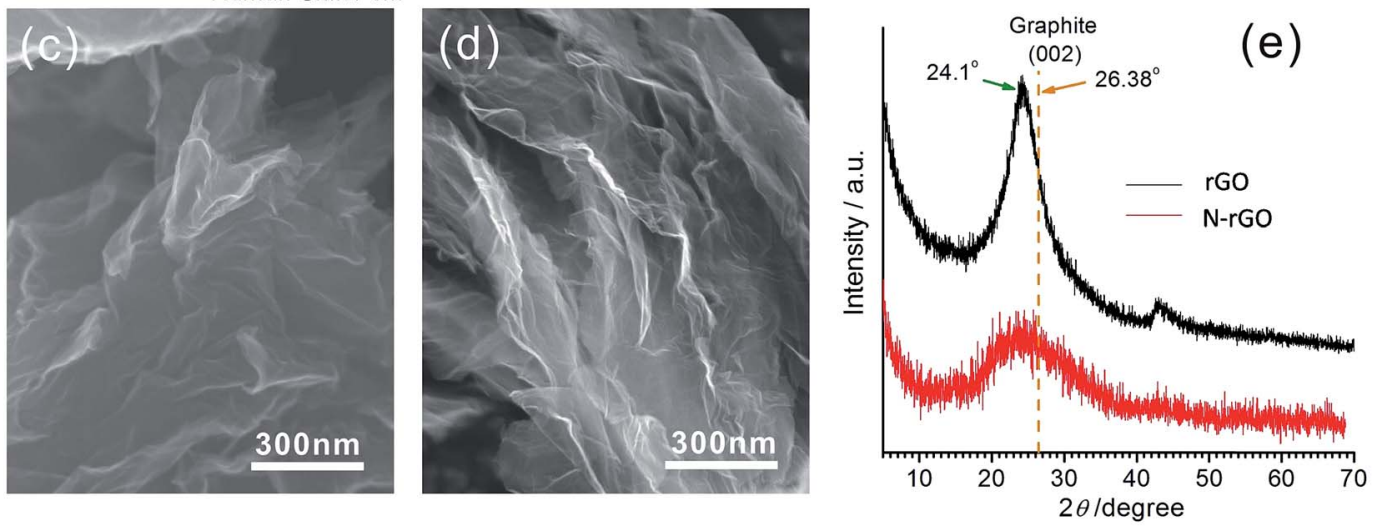

Fig. 1 (a) The Raman spectra of rGO and N-rGO. (b) A schematic of the molecular structures of rGO and N-rGO. SEM images of (c) rGO and (d) $\mathrm{N}$-rGO. (e) XRD patterns of $r G O$ and $N$-rGO 


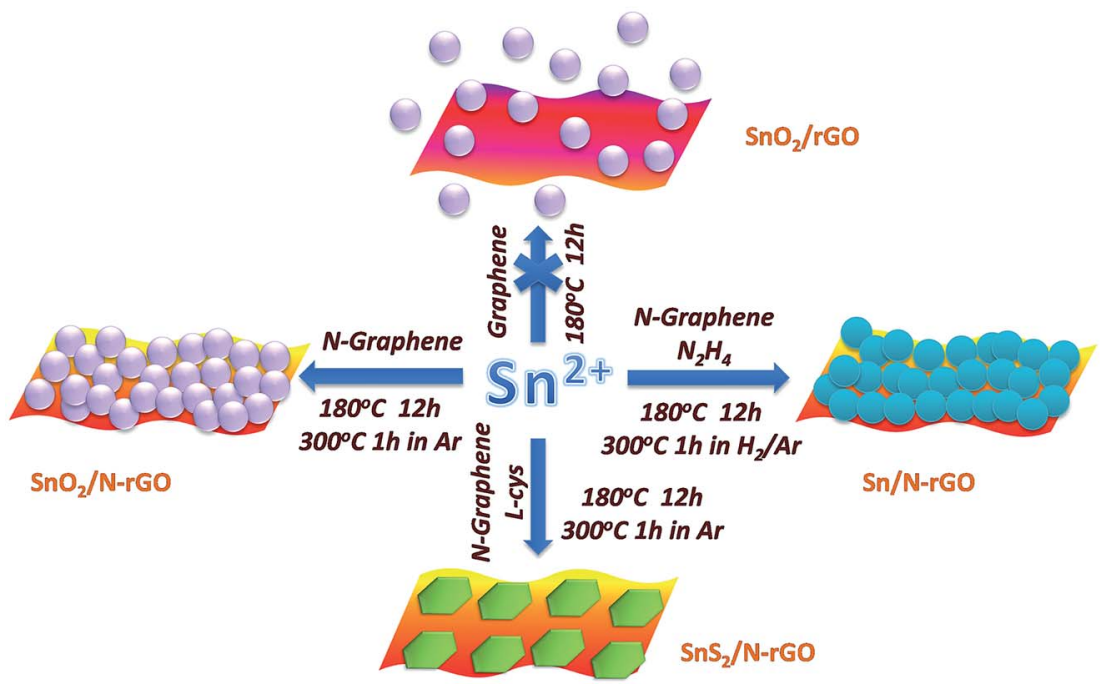

Fig. 2 A schematic of the synthetic routes used to prepare the Sn-based materials supported on $r G O$ and N-rGO.

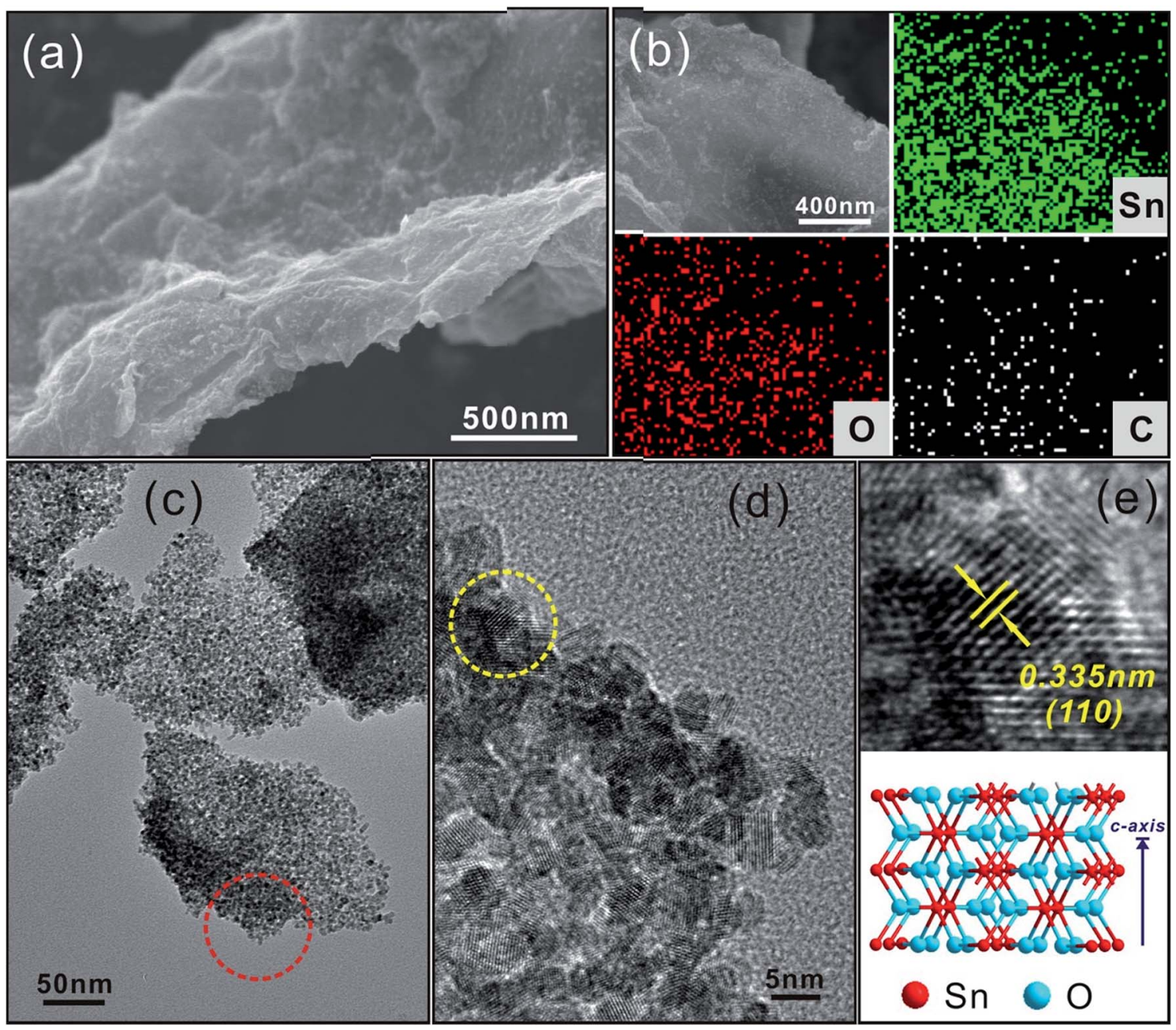

Fig. 3 The morphology and structure of $\mathrm{SnO}_{2} / \mathrm{N}-\mathrm{rGO}$ : (a) $\mathrm{SEM}$ image of $\mathrm{SnO}_{2} / \mathrm{N}-\mathrm{rGO}$, (b) EDS mapping for each element, (c) TEM image of the $\mathrm{SnO}_{2} / \mathrm{N}-\mathrm{rGO}$ composite, (d) the magnified area shown in (c), (e) the HRTEM image of the selected area shown in (d), and a schematic of the molecular structure of $\mathrm{SnO}_{2}$. 
to form a slurry, which was subsequently spread onto a copper foil with a thickness of $0.1 \mathrm{~mm}$ and a diameter of $12 \mathrm{~mm}$, dried at $80{ }^{\circ} \mathrm{C}$ in a drying oven for $2 \mathrm{~h}$, compacted using a hydraulic press, and then dried again at $120{ }^{\circ} \mathrm{C}$ for $12 \mathrm{~h}$ in a vacuum drying chamber. Button cells (2025R) containing a Li foil as a counter electrode, polypropylene film (Celgard 2400) as a separator, and $1 \mathrm{M}\left(\mathrm{mol} \mathrm{L}^{-1}\right) \mathrm{LiPF}_{6}$ in a mixture of ethylene carbonate/dimethyl carbonate/diethyl carbonate (EC/DMC/DEC $1: 1: 1$ by volume) as an electrolyte were assembled in an argon-filled glovebox. Constant-current charge and discharge tests were performed using a cell test system (Land CT2001A) in the potential range between 0.005 and $3.0 \mathrm{~V}$. Cyclic voltammetry (CV) tests were carried out using an electrochemical workstation (CHI 660C) over a potential range from 0.005 to $3.0 \mathrm{~V}$ at a scan rate of $0.1 \mathrm{mV} \mathrm{s}^{-1}$. Electrochemical impedance tests were also performed using an electrochemical workstation (CHI 660C) over the frequency range from $0.01 \mathrm{~Hz}$ to $100 \mathrm{kHz}$ at an amplitude of $5 \mathrm{mV}$.

\section{Results and discussion}

The proposed rGO and N-rGO were synthesized using the method described in the Experimental section. According to the calculation in XPS spectrum of N-rGO, the atomic ratio of the doped nitrogen was estimated to be 2.3 at\% (Fig. S2 $\dagger$ ). Fig. 1 shows the characterization results for the as-prepared rGO and $\mathrm{N}$-rGO. Upon comparing their Raman spectra shown in Fig. 1a, it was found that the $\mathrm{D}$ band observed at approximately $1350 \mathrm{~cm}^{-1}$ was disorder-induced and attributed to the structural defect sites on the rGO plane. The G band observed at approximately $1600 \mathrm{~cm}^{-1}$ is commonly observed for all graphitic structures and attributed to the $\mathrm{E}_{2 \mathrm{~g}}$ vibrational mode present in the $\mathrm{sp}^{2}$-bonded graphitic carbons. The intensity ratio of the D peak to $\mathrm{G}$ peak, i.e. $I_{\mathrm{D}} / I_{\mathrm{G}}$, provides an indication of the amount of structural defect sites and is a quantitative measure of edge plane exposure. It can be clearly observed from Fig. 1a that the $I_{\mathrm{D}} / I_{\mathrm{G}}$ ratio of $\mathrm{N}-\mathrm{rGO}$ is obviously larger than that of $\mathrm{rGO}$ as a result of the structural defect sites caused by the incorporation of heterogeneous nitrogen atoms into the rGO layers. Their corresponding molecular structures are schematically illustrated in Fig. 1b, where the red balls represent the nitrogen atoms. At high temperatures, the partial active carbon atoms in rGO are easily replaced by the nitrogen atoms in ammonia gas to form N-rGO with more defects and vacancies. Upon comparing the FESEM images of rGO (Fig. 1c) and N-rGO (Fig. 1d), it has also been found that N-rGO possesses a rougher and more wrinkled surface than rGO. Moreover, after nitrogen doping, the rGO nanosheets become thinner, which can be observed from the XRD patterns shown in Fig. 1e. The diffraction peaks observed at $2 \theta=24.1^{\circ}$, which are attributed to the (002) plane of the rGO and N-rGO nanosheets, have the slightly larger interlayer distance than that of graphite, with the diffraction peak of (002) at $2 \theta=26.38^{\circ}$. In addition, the (002) peak intensity of $\mathrm{N}-\mathrm{rGO}$ was obviously lower than that of rGO;

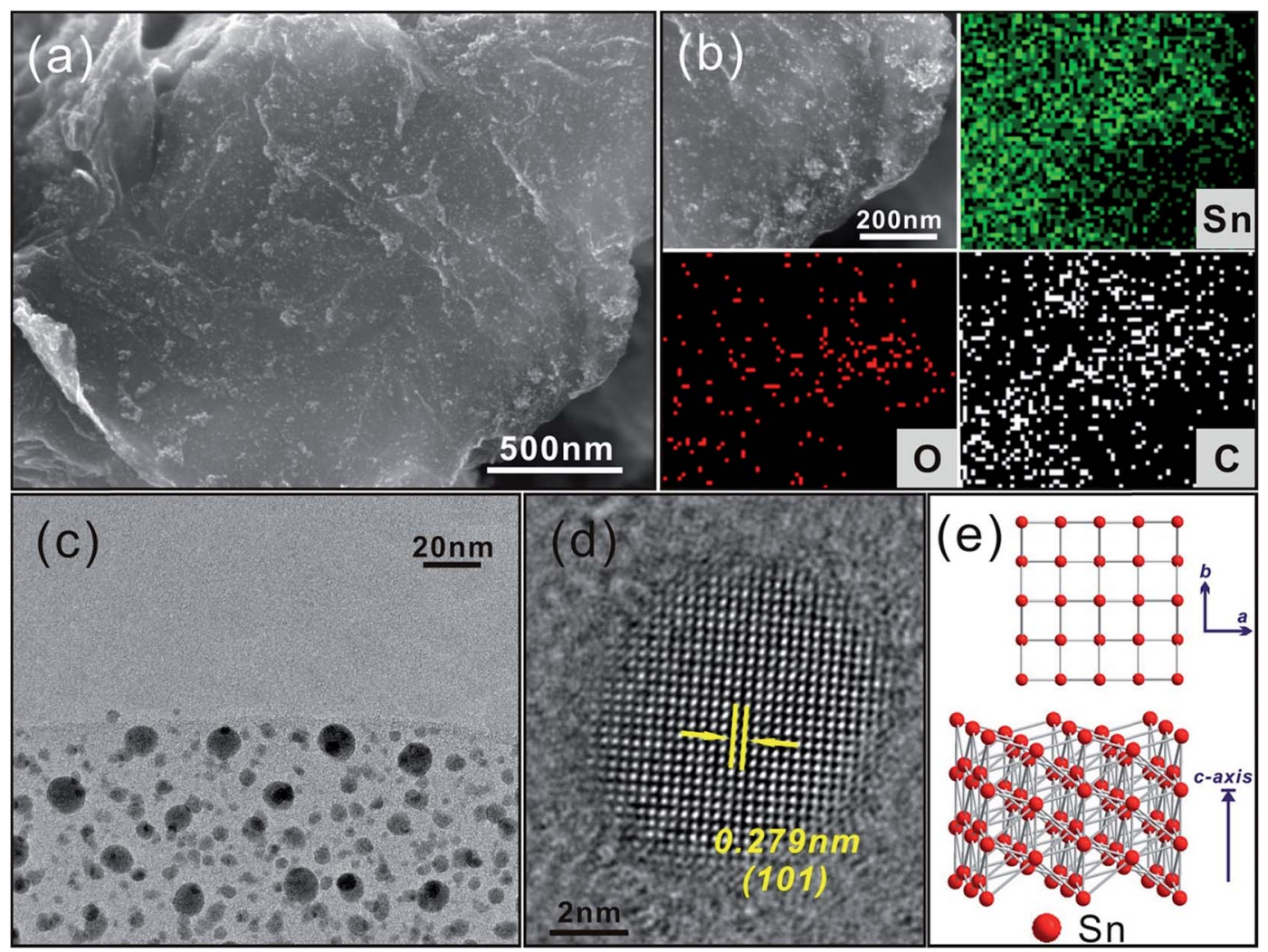

Fig. 4 The morphology and structure of Sn/N-rGO: (a) SEM image of Sn/N-rGO, (b) corresponding EDS mapping for each element, (c) TEM image of the Sn/N-rGO composite, (d) HRTEM image of Sn/N-rGO, and (e) a schematic of the atomic structure of Sn. 
this indicated that the restacking degree of the N-rGO nanosheets along $c$-axis was lower than that found in the case of the rGO nanosheets as well as illustrated that the nanosheets for $\mathrm{N}$-rGO were more thinner.

Using N-rGO as a template, the Sn-based materials were anchored in situ on the surface of N-rGO via a solution-phase method. Fig. 2 illustrates schematically the synthesis routes used to prepare the Sn-based materials supported on N-rGO, in which $\mathrm{Sn}^{2+}$ ions are the starting materials. While using rGO as the template, the hydrolyzed $\mathrm{SnO}_{2}$ nanoparticles were not adsorbed on the surface of the rGO nanosheets. It can also be observed in Fig. $\mathrm{S} 3 \uparrow$ that the $\mathrm{SnO}_{2}$ nanoparticles are separated from the rGO nanosheets. As abovementioned, this may be attributed to the smooth surface of the rGO nanosheets obtained through the thermal exfoliation process, which does not provide nucleation sites for the $\mathrm{SnO}_{2}$ nanoparticles. Thus, $\mathrm{N}$-rGO with more defect sites and vacancies was used as the template for the nucleation of $\mathrm{SnO}_{2}$ nanoparticles. ${ }^{32}$

Fig. 3 shows the morphology and structure of $\mathrm{SnO}_{2} / \mathrm{N}-\mathrm{rGO}$. The FESEM image, as shown in Fig. 3a, indicates that the $\mathrm{SnO}_{2}$ nanocrystals are densely anchored on the surface of the $\mathrm{N}$ rGO nanosheets; this is caused by the large number of defects and vacancies in N-rGO. The elemental mapping images shown in Fig. 3b reveal that the $\mathrm{Sn}, \mathrm{O}$, and $\mathrm{C}$ elements are uniformly dispersed on the N-rGO nanosheets. The TEM images, as shown in Fig. $3 \mathrm{c}$ and d, show that the average size of the $\mathrm{SnO}_{2}$ nanocrystals is around 3-4 nm, and from the HRTEM image (Fig. 3e), it can be seen that the lattice fringes of $0.335 \mathrm{~nm}$ correspond to the (110) planes of tetragonal $\mathrm{SnO}_{2}$. The XRD pattern of $\mathrm{SnO}_{2} / \mathrm{N}-$ rGO is shown in Fig. S4. $\dagger$ All the peaks can be indexed to tetragonal $\mathrm{SnO}_{2}$ (JCPDS 41-1445), and the corresponding molecular structure is illustrated in Fig. 3e.

The $\mathrm{Sn} / \mathrm{N}-\mathrm{rGO}$ composite was obtained from $\mathrm{SnO}_{2} / \mathrm{N}-\mathrm{rGO}$ by annealing at $300{ }^{\circ} \mathrm{C}$ in $\mathrm{H}_{2} / \mathrm{N}_{2}$ for $1 \mathrm{~h}$. The $\mathrm{SnO}_{2}$ nanoparticles were reduced to $\mathrm{Sn}$ metal under $\mathrm{H}_{2}$ during the high temperature treatment. Fig. 4 shows the morphology and structure of $\mathrm{Sn} / \mathrm{N}$ rGO, where it can be seen in Fig. 4a that the reduced Sn metal nanoparticles are homogeneously distributed on the surface of $\mathrm{N}$-rGO. The element mapping images shown in Fig. $4 \mathrm{~b}$ reveal that the composites mainly contain the elements $\mathrm{Sn}$ and $\mathrm{C}$ as well as a small amount of $\mathrm{O}$ derived from the oxygen functional groups of $\mathrm{N}-\mathrm{rGO}$ and non-reduced $\mathrm{SnO}_{2}$. The TEM image in Fig. $4 \mathrm{c}$ indicates that the $\mathrm{Sn}$ particle size ranges from 5 to $10 \mathrm{~nm}$, and from the HRTEM image (Fig. 4d), it can be seen that the lattice fringes of $0.279 \mathrm{~nm}$ correspond to the (101) planes of tetragonal Sn. Fig. S5† shows the XRD pattern of the $\mathrm{Sn} / \mathrm{N}-\mathrm{rGO}$

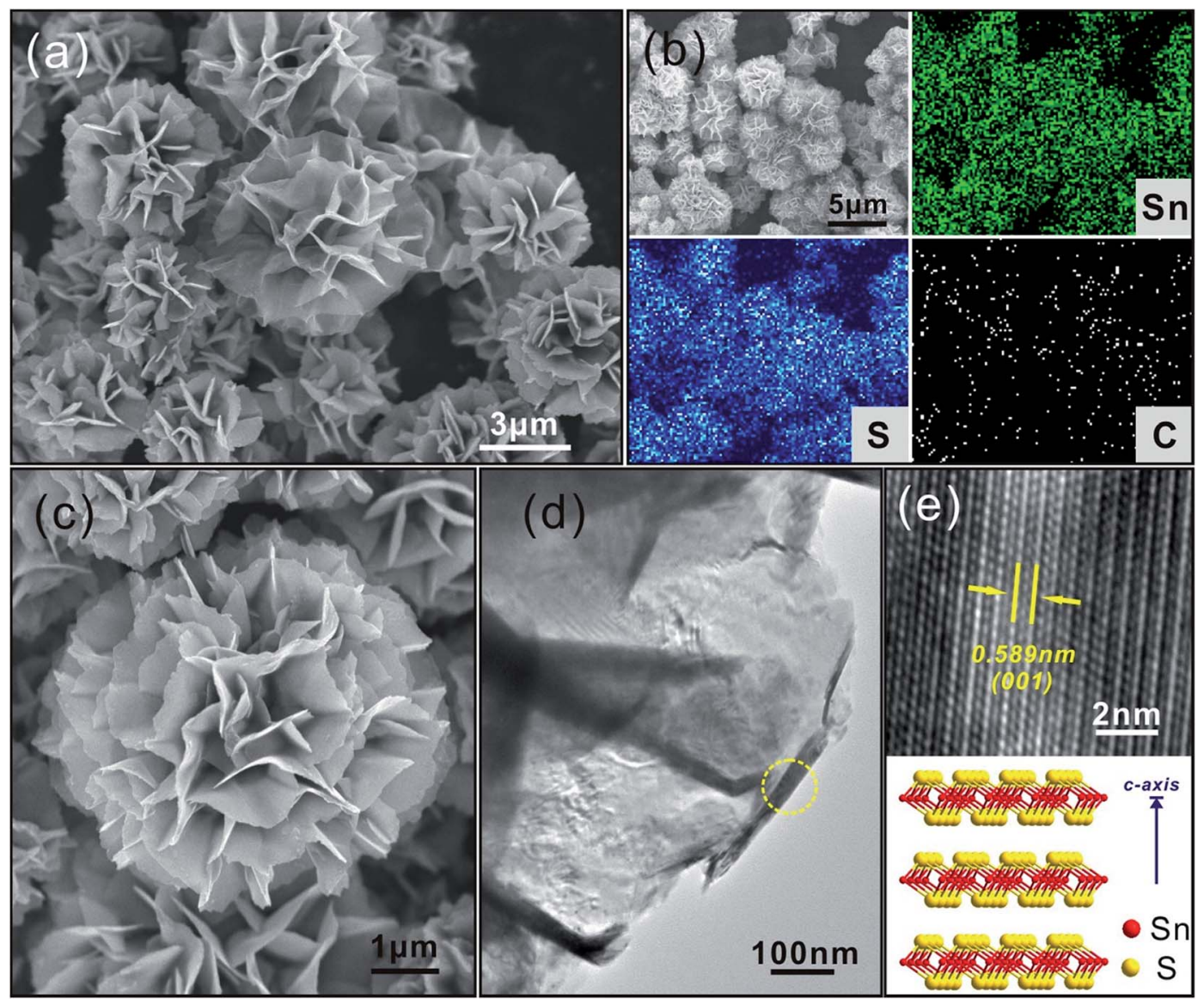

Fig. 5 The morphology and structure of $\mathrm{SnS}_{2} / \mathrm{N}-\mathrm{rGO}$ : (a) SEM image of $\mathrm{SnS}_{2} / \mathrm{N}-\mathrm{rGO}$, (b) EDS mapping for each element, (c) the enlarged SEM image of the flower-like $\mathrm{SnS}_{2} / \mathrm{N}$-rGO composite, (d) TEM image of the $\mathrm{SnS}_{2} / \mathrm{N}-\mathrm{rGO}$ sheets and (e) the HRTEM image of the selected area shown in (d), and a schematic of the molecular structure of $\mathrm{SnS}_{2}$. 
composite, where it can be observed that all the diffraction peaks for the composites correspond well to the tetragonal crystalline phase of Sn (JCPDS 04-0673), which corresponds to the molecular structure illustrated in Fig. 4e.

Using a similar process as that used to prepare $\mathrm{SnO}_{2} / \mathrm{N}-\mathrm{rGO}$, $\mathrm{SnS}_{2} / \mathrm{N}-\mathrm{rGO}$ was synthesized by adding L-cysteine (L-cys) as the sulfur source. Upon comparing the morphologies of $\mathrm{SnO}_{2} / \mathrm{N}$ rGO and Sn/N-rGO, which show zero-dimensional (OD) materials composited with two-dimensional (2D) materials, it has been observed that $\mathrm{SnS}_{2} / \mathrm{N}-\mathrm{rGO}$ shows a double 2D material composite structure. Fig. 5a provides a general view of the $\mathrm{SnS}_{2} /$ $\mathrm{N}$-rGO composite, where it can be seen that the composite shows a three-dimensional (3D) architecture consisted of the curved nanosheets. According to previous reports, ${ }^{3,33}$ the selfassembly of the 3D architecture materials was facile under the L-cys-assisted hydrothermal conditions due to the network structure of the L-cys molecule.

In this study, the self-assembly was promoted under the condition that layered $\mathrm{SnS}_{2}$ and $\mathrm{rGO}$ were involved depending on their interactions. The elemental mapping images shown in Fig. $5 \mathrm{~b}$ reveal that $\mathrm{SnS}_{2} / \mathrm{N}-\mathrm{rGO}$ mainly contains the elements $\mathrm{Sn}$, $\mathrm{S}$, and $\mathrm{C}$, which are uniformly distributed in the composites. Fig. $5 \mathrm{c}$ and d indicate that $\mathrm{SnS}_{2}$ and N-rGO deliver matched 2D layered structures, which are tightly composited together. The XRD pattern of $\mathrm{SnS}_{2} / \mathrm{N}$-rGO in Fig. S6 $\dagger$ also shows that all the diffraction peaks can be attributed to layered hexagonal $\mathrm{SnS}_{2}$ corresponding to the JCPDS card no. 23-0677. It can be calculated from the $d$ spacing of the (001) peak at $2 \theta=15.1^{\circ}$ according to the diffraction angles using the Bragg equation that the interlayer distance of $\mathrm{SnS}_{2}$ is $0.59 \mathrm{~nm}$, which is in accordance with the measurement results shown in the HRTEM image shown in Fig. 5e. When used as the anode material in an LIB, this 2D layered structure (Fig. 5e, illustration of the $\mathrm{SnS}_{2}$ molecular structure) could buffer the volume change and improve the cycling stability of the electrodes. ${ }^{34,35}$

To investigate the effect of N-rGO on the electrochemical performance of the composites, we undertook electrical tests using different samples. According to the elemental analysis of EDS (Table S1 $\dagger$ ), it can be seen that the amount of N-rGO was lower than $3 \mathrm{wt} \%$ in the three composites; therefore, the Snbased materials still acted as the major active electrode material in our experiments. Fig. 6 shows the first three charge/ discharge profiles of the three composite samples between

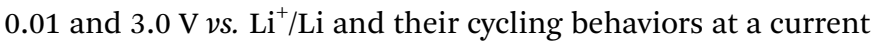
density of $100 \mathrm{~mA} \mathrm{~h} \mathrm{~g}{ }^{-1}$. All the specific capacities given below are calculated based on the whole composites. Upon comparing the three initial discharge curves of $\mathrm{Sn} / \mathrm{N}-\mathrm{rGO}, \mathrm{SnO}_{2} / \mathrm{N}-\mathrm{rGO}$, and $\mathrm{SnS}_{2} / \mathrm{N}-\mathrm{rGO}$, it was found that an inconspicuous potential plateau appeared at $1.8 \mathrm{~V}$ for $\mathrm{SnS}_{2} / \mathrm{N}-\mathrm{rGO}$ (Fig. $6 \mathrm{c}$ ), which could be attributed to the formation of $\mathrm{Li}_{x} \mathrm{SnS}_{2}$ when lithium ions were intercalated into the $\mathrm{SnS}_{2}$ layers to some extent without causing phase decomposition. ${ }^{36}$ For $\mathrm{SnO}_{2} / \mathrm{N}$-rGO (Fig. 6b), this
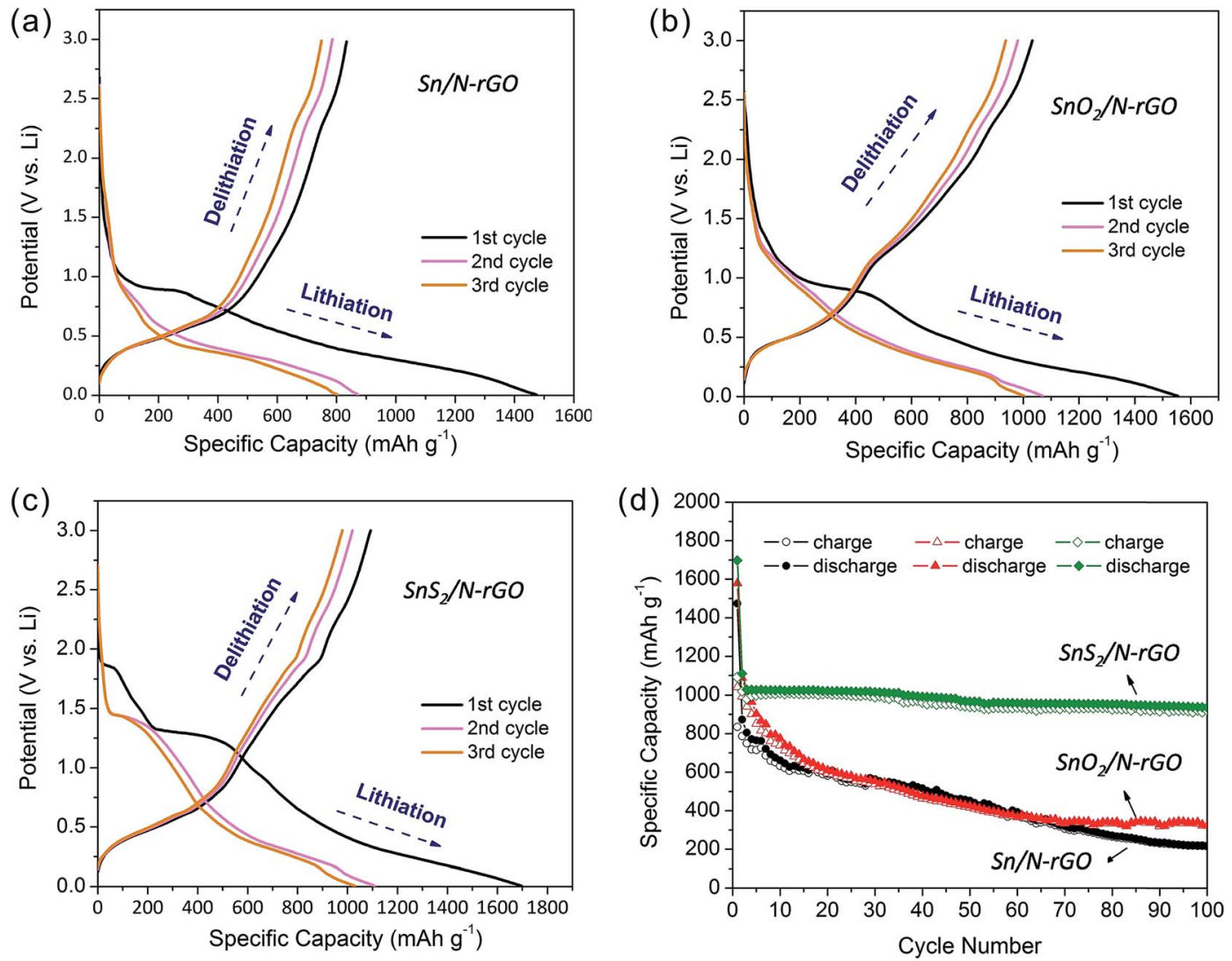

Fig. 6 The galvanostatic charge and discharge curves obtained for the (a) $\mathrm{Sn} / \mathrm{N}-\mathrm{rGO}$, (b) $\mathrm{SnO}_{2} / \mathrm{N}-\mathrm{rGO}$, and (c) SnS $/ 2 / \mathrm{N}-\mathrm{rGO}$ nanocomposites, and (d) their cycling behaviors at a current density of $100 \mathrm{~mA} \mathrm{~h} \mathrm{~g}^{-1}$. 
inconspicuous potential plateau appeared at $1.4 \mathrm{~V}$, whereas no potential plateau was observed for $\mathrm{Sn} / \mathrm{N}-\mathrm{rGO}$. The irreversible plateaus that emerged at $1.3 \mathrm{~V}$ for $\mathrm{SnS}_{2} / \mathrm{N}-\mathrm{rGO}$ and $1.0 \mathrm{~V}$ for $\mathrm{SnO}_{2} / \mathrm{N}-\mathrm{rGO}$ and $\mathrm{Sn} / \mathrm{N}-\mathrm{rGO}$ can be assigned to the formation of $\mathrm{Sn}$ and $\mathrm{Li}_{2} \mathrm{~S}$ or $\mathrm{Li}_{2} \mathrm{O},{ }^{37-39}$ where oxygen in the $\mathrm{Sn} / \mathrm{N}-\mathrm{rGO}$ composite originates from the oxygen functional groups in $\mathrm{N}$ rGO (Fig. 4b). In the potential range from 0.01 to $0.5 \mathrm{~V}$, lithium ions alloyed with the $\mathrm{Sn}$ metal form a series of $\mathrm{Li}-\mathrm{Sn}$ alloys. During the subsequent cycles, the lithiation and delithiation process can be attributed to the following two reactions: $\mathrm{Li}_{2} \mathrm{~S}$ (or $\mathrm{Li}_{2} \mathrm{O}$ ) $\leftrightarrow 2 \mathrm{Li}+\mathrm{S}$ and $\mathrm{Li}_{x} \mathrm{Sn} \leftrightarrow x \mathrm{Li}+\mathrm{Sn}^{40}$ Correspondingly, the charge and discharge voltage plateaus characteristic for the three Sn-based N-rGO composites were assigned to their cyclic voltammograms curves (Fig. S7 $\dagger$ ).

In Fig. 6a-c, the initial charge capacity observed for $\mathrm{Sn} / \mathrm{N}$ $\mathrm{rGO}, \mathrm{SnO}_{2} / \mathrm{N}-\mathrm{rGO}$, and $\mathrm{SnS}_{2} / \mathrm{N}-\mathrm{rGO}$ was $834.3,1041.3$, and $1093 \mathrm{~mA} \mathrm{~h} \mathrm{~g}^{-1}$, and the discharge capacity was $1473.8,1579.2$, and $1697.3 \mathrm{~mA} \mathrm{~h} \mathrm{~g}{ }^{-1}$, respectively. The initial irreversible capacity can be attributed to the formation of a solid electrolyte interface (SEI) layer and the side reactions of the electrolyte. ${ }^{\mathbf{4 1}}$ All three composites exhibit a high charge/discharge capacity when compared with bare Sn-based materials. ${ }^{\mathbf{1 6 4 2 - 4 4}}$ Among these, the $\mathrm{SnS}_{2} / \mathrm{N}-\mathrm{rGO}$ composite shows the highest specific capacity, and the higher capacity of $\mathrm{SnO}_{2} / \mathrm{N}-\mathrm{rGO}$ and $\mathrm{SnS}_{2} / \mathrm{N}$ rGO than $\mathrm{Sn} / \mathrm{N}-\mathrm{rGO}$ is assigned to the contribution of the $\mathrm{O}$ and $\mathrm{S}$ elements in the composites. The drastic enhancement in the specific capacity is attributed to the cooperation of N-rGO, which provides a large surface for anchoring the Sn-based materials uniformly and high conductivity for electron transport. ${ }^{\mathbf{4 4 , 4 5}}$ As is known, the main drawback of Sn-based materials as LIB electrodes is their volume change during cycling that leads to rapid capacity fading. Carbon materials, such as amorphous carbon, rGO, and N-rGO, are usually coated on Snbased materials to buffer the volume change of these materials. In our study, we also used N-rGO as the substrate to support the Sn-based materials to avoid their capacity fading. However, as seen in Fig. 6d, the cycling behavior of the three Sn-based materials showed that only the $\mathrm{SnS}_{2} / \mathrm{N}$-rGO composite exhibited good stability. After 100 cycles, the reversible capacity of $\mathrm{SnS}_{2} / \mathrm{N}$-rGO was still $920.6 \mathrm{~mA} \mathrm{~h} \mathrm{~g}^{-1}$ with a capacity retention of $84.2 \%$. On the contrary, the $\mathrm{Sn} / \mathrm{N}-\mathrm{rGO}$ and $\mathrm{SnO}_{2} / \mathrm{N}-\mathrm{rGO}$ composites deliver the poor cycling abilities with a reversible capacity retention of only $25.8 \%$ and $31.0 \%$ after 100 cycles. In general, the capacity fading was caused by the expansive volume excursions in the active electrode materials during the charging and discharging, leading to the pulverization of material and loss of electrical connectivity. Due to the mismatched structure of zero-dimensional $\mathrm{Sn}$ and $\mathrm{SnO}_{2}$ nanoparticles with twodimensional $\mathrm{N}-\mathrm{rGO}$, the electrode active materials are easily exfoliated during the charge/discharge process. ${ }^{8}$ The $\mathrm{SnS}_{2} / \mathrm{N}$ rGO composite maintain good stability during the charge/ discharge process due to its matched and robust structure formed between the two-dimensional layered $\mathrm{SnS}_{2}$ and $\mathrm{N}$-rGO.

Fig. 7a shows the rate cycling behavior of the three Sn-based composite electrodes. The high reversible capacity and excellent cycling behavior of the $\mathrm{SnS}_{2} / \mathrm{N}$-rGO composite are reflected in their high rate capabilities. The average specific capacities (a)

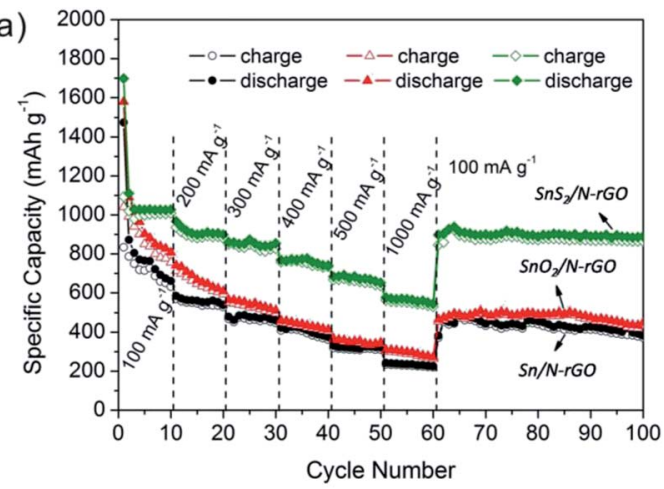

(b)

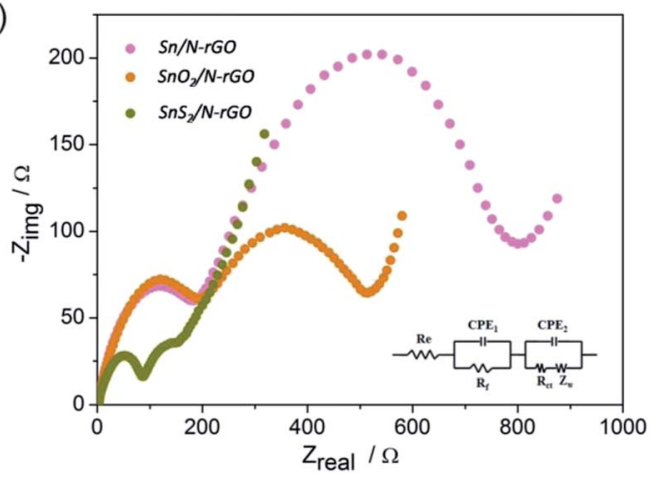

Fig. 7 (a) The cycling behavior of the Sn-based composites at various current densities and (b) their corresponding Nyquist plots. The inset shows the equivalent circuit model of the studied system and CPE represents the constant phase element, $Z_{\mathrm{CPE}}=\left\{Q(j \omega)^{n}\right\}^{-1}, 0 \leq n \leq 1$.

observed for the $\mathrm{SnS}_{2} / \mathrm{N}-\mathrm{rGO}$ composite are 1034, 918, 852, 772, 678 , and $567 \mathrm{~mA} \mathrm{~h} \mathrm{~g}^{-1}$ at the current densities of 100, 200, 300, 400, 500, and $1000 \mathrm{~mA} \mathrm{~g}^{-1}$, respectively. Remarkably, after cycling at $1000 \mathrm{~mA} \mathrm{~g}^{-1}$, a stable capacity of $\sim 900 \mathrm{~mA} \mathrm{~h} \mathrm{~g}^{-1}$ was still delivered when the current density was reduced back to $100 \mathrm{~mA} \mathrm{~g}^{-1}$; this indicated high cycling stability. However, the $\mathrm{Sn} / \mathrm{N}-\mathrm{rGO}$ and $\mathrm{SnO}_{2} / \mathrm{N}$-rGO composites deliver a reversible capacity of only $200-300 \mathrm{~mA} \mathrm{~h} \mathrm{~g} \mathrm{~g}^{-1}$ at a current density of $1000 \mathrm{~mA} \mathrm{~g}^{-1}$, exhibiting a poor rate capability.

To further explain and better understand why the $\mathrm{SnS}_{2} / \mathrm{N}$ rGO electrode exhibits superior electrochemical performance as compared to the $\mathrm{Sn} / \mathrm{N}-\mathrm{rGO}$ and $\mathrm{SnO}_{2} / \mathrm{N}-\mathrm{rGO}$ electrodes, electrochemical impedance measurements have been performed after 3 cycles, as shown in Fig. 7b. The equivalent circuit model of the studied system is shown in the inset image of Fig. $7 \mathrm{~b}$.

The kinetic differences in the three Sn-based composite electrodes were further investigated by electrochemical impedance spectrum (EIS) modeling based on the modified equivalent circuit ${ }^{46}$ using the fitted impedance parameters listed in Table 1.

In this model system, $R_{\mathrm{e}}$ represents the internal resistance of the test battery, $R_{\mathrm{f}}$ and $\mathrm{CPE}_{1}$ are associated with the resistance and constant phase element of the SEI film, $R_{\text {ct }}$ and $\mathrm{CPE}_{2}$ are associated with the charge-transfer resistance and constant phase element of the electrode/electrolyte interface, respectively, and $Z_{\mathrm{W}}$ is associated with the Warburg impedance corresponding to the lithium-diffusion process. In Fig. 7b, the high 
Table 1 The impedance parameters derived using an equivalent circuit model for $\mathrm{Sn} / \mathrm{N}-\mathrm{rGO}, \mathrm{SnO}_{2} / \mathrm{N}-\mathrm{rGO}$, and $\mathrm{SnS}_{2} / \mathrm{N}-\mathrm{rGO}$

\begin{tabular}{llclcc}
\hline Electrodes & $R_{\mathrm{e}}(\Omega)$ & $R_{\mathrm{f}}(\Omega)$ & $\mathrm{CPE}_{1}(\mu \mathrm{F})$ & $R_{\text {ct }}(\Omega)$ & $\mathrm{CPE}_{2}(\mu \mathrm{F})$ \\
\hline $\mathrm{Sn} / \mathrm{N}-\mathrm{rGO}$ & 4.9 & 166.2 & 1.831 & 423.9 & 88.1 \\
$\mathrm{SnO}_{2} / \mathrm{N}-\mathrm{rGO}$ & 4.674 & 54.79 & 1.782 & 249.6 & 115.3 \\
$\mathrm{SnS}_{2} / \mathrm{N}-\mathrm{rGO}$ & 3.385 & 20.57 & 1.662 & 75.93 & 232
\end{tabular}

frequency semicircle corresponds to the resistance $R_{\mathrm{f}}$ and $\mathrm{CPE}_{1}$ of the SEI film, and the semicircle in the medium frequency region is assigned to the charge-transfer resistance $R_{\mathrm{ct}}$ and $\mathrm{CPE}_{2}$ of the electrode/electrolyte interface. The inclined line corresponds to the lithium-diffusion process within the bulk of the electrode material. From the analysis results, it is known that the SEI film resistance $R_{\mathrm{f}}$ and charge-transfer resistance $R_{\text {ct }}$ of the $\mathrm{SnS}_{2} / \mathrm{N}-\mathrm{rGO}$ electrode material are 20.57 and $75.93 \Omega$, respectively, which are significantly lower than those found for the $\mathrm{Sn} / \mathrm{N}-\mathrm{rGO}$ and $\mathrm{SnO}_{2} / \mathrm{N}$-rGO electrodes. These results confirm that the structurally matched $\mathrm{SnS}_{2} / \mathrm{N}-\mathrm{rGO}$ composite can provide more active sites and greater electrolyte-electrode contact area for lithium ion insertion and extraction as compared to the others. The incorporation of N-rGO does not only preserve the high conductivity of the composite, but also greatly enhances the rapid electron transport during the electrochemical lithium insertion/extraction process. In particular, for the layer structured $\mathrm{SnS}_{2} / \mathrm{N}-\mathrm{rGO}$ composite, its robust structure ensures its stability during the high rate cycle, resulting in a significant improvement in the electrochemical performance of the $\mathrm{SnS}_{2} / \mathrm{N}$-rGO composite.

\section{Conclusions}

In summary, a series of tin-based materials (including $\mathrm{Sn}, \mathrm{SnO}_{2}$, and $\mathrm{SnS}_{2}$ ) supported on N-rGO were successfully synthesized. When compared with pure rGO nanosheets, N-rGO provides more vacancies to provide nucleation sites for the Sn-based materials. The characterization results indicated that all the Sn-based materials were uniformly and tightly dispersed on the surface of N-rGO. In the three composites, the structural compatibility between the layer structured $\mathrm{SnS}_{2}$ and N-rGO suggested the possibility of designing a robust electrode as an LIB anode without the deficiency of most rGO composites with 0D metal oxides. The LIB test results indicated that among three samples, the $\mathrm{SnS}_{2} / \mathrm{N}-\mathrm{rGO}$ composite delivered the highest specific reversible capacity (1093 $\mathrm{mA} \mathrm{h} \mathrm{g}^{-1}$ ) with excellent cycling stability and high-rate capability. Upon comparing the three structural composites, it has been found that the impressive electrochemical performance observed for $\mathrm{SnS}_{2} / \mathrm{N}$ rGO can be attributed to its robust composite architecture that can withstand the stress of cycling as well as the complementary and synergistic interactions between the layered $\mathrm{SnS}_{2}$ and N-rGO structures.

\section{Conflicts of interest}

There are no conflicts to declare.

\section{Acknowledgements}

This work was financially supported by the Natural Science Foundation of China (No. 51672071), the Natural Science Foundation of China for Young (No. 21303042), and Science and Technology Research Projects of Henan Provincial Department (No. 132102210256).

\section{References}

1 M. Winter and R. J. Brodd, Chem. Rev., 2004, 104, 4245-4269. 2 K. Chang, W. X. Chen, L. Ma, H. Li, H. Li, F. H. Huang, Z. D. Xu, Q. B. Zhang and J. Y. Lee, J. Mater. Chem., 2011, 21, 6251-6257.

3 K. Chang and W. X. Chen, ACS Nano, 2011, 5, 4720-4728. 4 L. Shi, W. K. Wang, A. B. Wang, K. G. Yuan, Z. Q. Jin and Y. S. Yang, J. Power Sources, 2016, 318, 184-191.

5 D. M. Kang, Q. L. Liu, R. Si, J. J. Gu, W. Zhang and D. Zhang, Carbon, 2016, 99, 138-147.

6 Y. R. Ren and M. Q. Li, J. Power Sources, 2016, 306, 459466.

7 Y. Y. Li, H. Y. Zhang, Y. M. Chen, Z. C. Shi, X. G. Cao, Z. P. Guo and P. K. Shen, ACS Appl. Mater. Interfaces, 2016, 8, 197-207.

8 K. Chang, Z. Wang, G. C. Huang, H. Li, W. X. Chen and J. Y. Lee, J. Power Sources, 2012, 201, 259-266.

9 Y. H. Xu, J. C. Guo and C. S. Wang, J. Mater. Chem., 2012, 22, 9562-9567.

10 X. Xin, X. F. Zhou, F. Wang, X. Y. Yao, X. X. Xu, Y. M. Zhu and Z. P. Liu, J. Mater. Chem., 2012, 22, 7724-7730.

11 H. T. Kwon, C. K. Lee, K. J. Jeon and C. M. Park, ACS Nano, 2016, 10, 5701-5709.

12 H. X. Yang and L. Li, J. Alloys Compd., 2014, 584, 76-80.

13 P. Zhao, W. B. Yue, Z. X. Xu, S. M. Sun and H. Y. Bao, J. Alloys Compd., 2017, 704, 51-57.

14 S. Z. Liang, X. F. Zhu, P. C. Lian, W. S. Yang and H. H. Wang, J. Solid State Chem., 2011, 184, 1400-1404.

15 K. Nishikawa, K. Dokko, K. Kinoshita, S. W. Woo and K. Kanamura, J. Power Sources, 2009, 189, 726-729.

16 X. W. Lou, C. M. Li and L. A. Archer, Adv. Mater., 2009, 21, 2536-2539.

17 J. T. Zai, K. X. Wang, Y. Z. Su, X. F. Qian and J. S. Chen, J. Power Sources, 2011, 196, 3650-3654.

18 Y. Z. Jiang, T. Z. Yuan, W. P. Sun and M. Yan, ACS Appl. Mater. Interfaces, 2012, 4, 6216-6220.

19 J. Qin, C. N. He, N. Q. Zhao, Z. Y. Wang, C. S. Shi, E. Z. Liu and J. J. Li, ACS Nano, 2014, 8, 1728-1738.

20 K. Zhang, H. Yang, M. Lü, C. Yan, H. Wu, A. Yuan and S. Lin, J. Alloys Compd., 2018, 731, 646-654.

21 K. Chang, D. S. Geng, X. F. Li, J. L. Yang, Y. J. Tang, M. Cai, R. Y. Li and X. L. Sun, Adv. Energy Mater., 2013, 3, 839-844.

22 G. X. Wang, B. Wang, X. L. Wang, J. Park, S. X. Dou, H. Ahn and K. Kim, J. Mater. Chem., 2009, 19, 8378-8384.

23 Y. M. Li, X. J. Lv, J. Lu and J. H. Li, J. Phys. Chem. C, 2010, 114, 21770-21774.

24 L. S. Zhang, Y. P. Huang, Y. F. Zhang, W. Fan and T. X. Liu, ACS Appl. Mater. Interfaces, 2015, 7, 27823-27830. 
25 X. S. Zhou, J. C. Bao, Z. H. Dai and Y. G. Guo, J. Phys. Chem. C, 2013, 117, 25367-25373.

26 X. Q. Xie, D. W. Su, J. Q. Zhang, S. Q. Chen, A. K. Mondal and G. X. Wang, Nanoscale, 2015, 7, 3164-3172.

27 X. S. Zhou, L. J. Wan and Y. G. Guo, Adv. Mater., 2013, 25, 2152-2157.

28 F. H. Du, Y. S. Liu, J. Long, Q. C. Zhu, K. X. Wang, X. Wei and J. S. Chen, Chem. Commun., 2014, 50, 9961-9964.

29 J. Q. Shan, Y. X. Liu, P. Liu, Y. S. Huang, Y. Z. Su, D. Q. Wu and X. L. Feng, J. Mater. Chem. A, 2015, 3, 24148-24154.

30 Q. Wang, L. Xing and X. Xue, Mater. Lett., 2017, 209, 155-158.

31 W. S. Hummers and R. E. Offeman, J. Am. Chem. Soc., 1958, 80, 1339.

32 D. S. Geng, Y. Chen, Y. G. Chen, Y. L. Li, R. Y. Li, X. L. Sun, S. Y. Ye and S. Knights, Energy Environ. Sci., 2011, 4, 760-764.

33 K. Chang, W. X. Chen, H. Li and H. Li, Electrochim. Acta, 2011, 56, 2856-2861.

34 L. Wen, C. M. Liu, R. S. Song, H. Z. Luo, Y. Shi, F. Li and H. M. Cheng, Acta Chim. Sin., 2014, 72, 333-344.

35 Y. Jing, Z. Zhou, C. R. Cabrera and Z. F. Chen, J. Mater. Chem. A, 2014, 2, 12104-12122.

36 C. Julien and C. PerezVicente, Solid State Ionics, 1996, 89, 337-343.
37 C. Guan, X. H. Wang, Q. Zhang, Z. X. Fan, H. Zhang and H. J. Fan, Nano Lett., 2014, 14, 4852-4858.

38 J. Z. Chen, L. Yang, S. H. Fang, Z. X. Zhang, A. Deb and S. Hirano, Electrochim. Acta, 2014, 127, 390-396.

39 M. Alaf and H. Akbulut, J. Power Sources, 2014, 247, 692-702. 40 G. Kilibarda, S. Schlabach, V. Winkler, M. Bruns, T. Hanemann and D. V. Szabo, J. Power Sources, 2014, 263, 145-153.

41 W. L. Yao, J. Yang, J. L. Wang and Y. Nuli, J. Electrochem. Soc., 2008, 155, A903-A908.

42 H. Nara, Y. Fukuhara, A. Takai, M. Komatsu, H. Mukaibo, Y. Yamauchi, T. Momma, K. Kuroda and T. Osaka, Chem. Lett., 2008, 37, 142-143.

43 H. Mukaibo, A. Yoshizawa, T. Momma and T. Osaka, J. Power Sources, 2003, 119, 60-63.

44 H. B. Wang, T. Maiyalagan and X. Wang, ACS Catal., 2012, 2, 781-794.

45 D. Usachov, O. Vilkov, A. Gruneis, D. Haberer, A. Fedorov, V. K. Adamchuk, A. B. Preobrajenski, P. Dudin, A. Barinov, M. Oehzelt, C. Laubschat and D. V. Vyalikh, Nano Lett., 2011, 11, 5401-5407.

46 S. B. Yang, H. H. Song and X. H. Chen, Electrochem. Commun., 2006, 8, 137-142. 